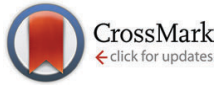

Cite this: J. Mater. Chem. C, 2016, 4, 5822

Received 17th March 2016, Accepted 25th May 2016

DOI: $10.1039 / \mathrm{c} 6 \mathrm{tc0} 01126 \mathrm{~h}$

www.rsc.org/MaterialsC

\section{Osmium-nitrido corroles as NIR indicators for oxygen sensors and triplet sensitizers for organic upconversion and singlet oxygen generation $\dagger$}

\author{
Sergey M. Borisov, ${ }^{* a}$ Abraham Alemayehu ${ }^{b}$ and Abhik Ghosh ${ }^{\text {b }}$ \\ The photophysical properties of nitridoosmium(vI) corroles have been investigated. The complexes exhibit \\ room temperature NIR phosphorescence $\left(\lambda_{\max } 779-795 \mathrm{~nm}\right)$. Long decay times $(110-150 \mu \mathrm{s}$ in solution \\ and $136-183 \mu \mathrm{s}$ in polystyrene) are responsible for efficient quenching of the emission by oxygen. All the \\ complexes act as efficient sensitizers of singlet oxygen (quantum yields of ${ }^{1} \mathrm{O}_{2}$ 0.76-0.95). Optical oxygen \\ sensors prepared on the basis of nitridoosmium(vı) corroles exhibit high photostability and excellent sensitivity \\ in the physiologically relevant range. The complexes have also been found to be promising sensitizers in \\ triplet-triplet annihilation-based upconversion systems. Finally and not least, simple synthetic accessibility \\ makes these dyes particularly attractive for application as optical materials.
}

\section{Introduction}

Dyes exhibiting room temperature phosphorescence find numerous applications, for example, as emitters in OLEDs, ${ }^{1,2}$ as probes for sensing $^{3}$ and imaging, ${ }^{4-6}$ and as sensitizers for triplet-triplet annihilation-based upconversion. ${ }^{7-10}$ NIR phosphorescent dyes are of particular interest ${ }^{11}$ and are used in NIR OLEDs, ${ }^{12-14}$ and solar concentrators. ${ }^{15}$ The combination of NIR emission with efficient absorption in the red part of the spectrum not only enables in vivo sensing and imaging of oxygen ${ }^{16-19}$ and glucose, ${ }^{20}$ but also makes the dyes promising for application in photon upconversion systems where harvesting of red light is of primary importance. Extended porphyrins, such as tetrabenzoporphyrins ${ }^{21,22}$ and tetranaphthoporphyrins, ${ }^{23,24}$ are probably the most common representatives of the dyes showing very strong NIR phosphorescence (phosphorescence quantum yields $\Phi \sim 0.1-0.6$ ). Several new classes of NIR phosphorescent dyes such as Pt(II) and Pd(II) complexes with donor-acceptor Schiff bases ${ }^{25}$ and Pt(II) hybrid complexes with BODIPY dyes ${ }^{26}$ exhibit moderate phosphorescence quantum yields (1-11\%). Other Pt(II) complexes with BODIPY dyes and naphthalene diimide chromophores coordinated via alkynyl linkages, however, exhibited even lower $\Phi$ that were well below $1 \% .^{27-30}$ Nevertheless, even in the absence of phosphorescent properties, dyes with high efficiency of inter-system crossing are very interesting

\footnotetext{
${ }^{a}$ Institute of Analytical Chemistry and Food Chemistry, NAWI Graz, Graz University of Technology, Stremayrgasse 9, 8010, Graz, Austria. E-mail: sergey.borisov@tugraz.at

${ }^{b}$ Department of Chemistry and Center for Theoretical and Computational Chemistry, UiT - The Arctic University of Norway, 9037 Tromsø, Norway. E-mail:abhik.ghosh@uit.no

$\dagger$ Electronic supplementary information (ESI) available. See DOI: 10.1039/c6tc01126h
}

as triplet sensitizers in photon upconversion and as singlet oxygen generators in photodynamic therapy. ${ }^{31,32}$

As porphyrin analogues with a rapidly unfolding chemistry, corroles are of considerable interest in this regard. A wide range of metallocorroles ${ }^{33-36}$ have been synthesized in recent years and several have witnessed applications as catalysts, ${ }^{37,38}$ in chemical sensing, ${ }^{39}$ and in the biomedical arena. ${ }^{40}$ Many of them exhibit bright fluorescence; ${ }^{41,42}$ only a few, however, have been shown to possess NIR phosphorescence at room temperature. The latter class of complexes includes iridium corroles, ${ }^{43,44}$ a gold(III) $\beta$-octabromocorrole, ${ }^{45}$ and aluminium and gallium complexes of $\beta$-iodinated corroles. ${ }^{46} \mathrm{~A}$ variety of other $5 \mathrm{~d}$ metallocorroles, including rhenium, ${ }^{47}$ osmium, ${ }^{48}$ gold ${ }^{49-51}$ and platinum ${ }^{52}$ corroles, which might be expected to exhibit NIR phosphorescence, have been synthesized in recent years. Given the steric mismatch of a large $5 \mathrm{~d}$ metal and the constricted $\mathrm{N} 4$ cavity of a corrole, many of the syntheses are capricious and low-yielding. The nitridoosmium(vi) corroles, however, are accessible simply and in good yields, prompting us to examine their photophysical properties. Although they exhibit only moderate NIR phosphorescence, the OsN corroles are notable for their exceptional chemical and photochemical stability and exhibit considerable promise as oxygen sensors, triplet sensitizers in upconversion systems, and as singlet oxygen photosensitizers.

\section{Experimental}

\section{Materials}

The osmium-nitrido corrole complexes were prepared according to a recently reported procedure. ${ }^{48}$ The annihilators for 
upconversion experiments, perylene and solvent green 5 (=SG 5, diisobutyl 3,9-perylenedicarboxylate) were obtained from Fluka and ABCR (Karlsruhe, Germany), respectively. 9,10-Dimethylanthracene and methylene blue were acquired from TCI Europe and Sigma-Aldrich, respectively.

\section{Preparation of oxygen sensors}

The dye $(1 \mathrm{mg})$, polystyrene (Acros Organics, $M_{\mathrm{W}} 250000,100 \mathrm{mg}$ ) and lipophilic titanium dioxide nanoparticles (P170, Kemira, $50 \mathrm{mg}$ ) were dissolved/dispersed in chloroform (1.35 g). The "cocktail" obtained was knife-coated onto a polyethylene terephthalate support (Melinex 505, Pütz, Taunusstein, Germany), yielding $\sim 7 \mu \mathrm{m}$ thin films after evaporation of the solvent. For acquisition of absorption and emission spectra, a "cocktail" was prepared analogously but with no added titanium dioxide.

\section{Measurements}

Absorption spectra were acquired on a Cary 50 UV-Vis spectrophotometer (Varian). Emission spectra were measured on a Fluorolog 3 fluorescence spectrometer from Horiba (Japan) equipped with a NIR-sensitive photomultiplier R2658 from Hamamatsu (Japan), all spectra being corrected for the sensitivity of the photomultiplier. The luminescence quantum yields in solution were measured relative to platinum(II) tetraphenyltetrabenzoporphyrin (PtTPTBP, QY 51\%). ${ }^{53}$ The solutions were placed in sealable quartz cells (Hellma Analytics, Mülheim, Germany) and deoxygenated by bubbling argon (5.0, Linde gas, Austria) for $15 \mathrm{~min}$. Absolute quantum yields for the sensor foils were acquired in an integrating sphere from Horiba.

The photostability of the dyes was investigated by irradiating air-saturated dye solutions in toluene $\left(1.4 \times 10^{-5} \mathrm{M}\right)$ with the light of a high power orange LED array $\left(\lambda_{\max } 590 \mathrm{~nm}\right.$, www.led-tech.de) operated at $27 \mathrm{~V}$ and $0.6 \mathrm{~A}$. The light was additionally focused through a lens (Edmunds Optics) to result in a photon flux density of $\sim 10800 \mu \mathrm{mol} \mathrm{s}^{-1} \mathrm{~m}^{-2}$ or $0.22 \mathrm{~W} \mathrm{~cm}^{-2}$ as determined with a Li-250A light meter from Li-COR (www.licor.com). The cuvette with the solution was shaken after each irradiation period before absorbance measurement.

Luminescence decay times in deoxygenated toluene were measured in the frequency domain using a lock-in amplifier from PreSens (Regensburg, Germany). The solutions were excited with light from a $590 \mathrm{~nm}$ LED filtered through a NIR-blocking filter Calflex X (transmittance of $50 \%$ at $730 \mathrm{~nm}$; Linos) and the emission was detected with a photodiode equipped with a longpass RG 780 filter (transmittance of $50 \%$ at $780 \mathrm{~nm}$; Schott). A modulation frequency of $916 \mathrm{~Hz}$ was used.

The oxygen sensors were characterized in the frequency domain with a two-phase lock-in amplifier (SR830, Stanford Research, Inc., USA). The excitation light was provided by a $455 \mathrm{~nm}$ LED (Roithner Lasertechnik, Austria). The light was sinusoidally modulated at $1150 \mathrm{~Hz}$ and filtered through a BG-12 band-pass filter (transmission range 300-520 nm; Schott). The emission light (filtered through an RG 780 filter) was recorded by a photomultiplier tube (H5701-02, Hamamatsu, Japan). Gas calibration mixtures were obtained from nitrogen and compressed air using a gas mixing device from MKS (Andover, MA, USA).
The temperature was controlled with a ThermoHaake DC50 cryostat (Thermo Fisher Scientific, Inc).

Triplet-triplet annihilation upconversion was studied on Fluorolog 3 fluorescence spectrometer. The anoxic toluene solutions containing $1 \times 10^{-4} \mathrm{M}$ of an $\mathrm{Os}^{\mathrm{VI}} \mathrm{N}$ corrole and $2.5 \times 10^{-4} \mathrm{M}$ of the annihilator were excited at $595 \mathrm{~nm}$ (14 nm slits). The intensity dependency of the upconversion emission was acquired with neutral density filters from Schott (NG 11, NG 4, NG 3 and NG 9) with transmission at $595 \mathrm{~nm}$ of $77.8 \%, 34.3 \%, 9.4 \%$ and $4.4 \%$, respectively.

Singlet oxygen quantum yields were determined by a relative method using 9,10-dimethylanthracene (DMA) as singlet oxygen acceptor. ${ }^{54} 2.5 \mathrm{~mL}$ of solution of DMA $(0.28 \mathrm{mM})$ and a sensitizer $(\sim 15 \mu \mathrm{M}$, adjusted for identical absorption of the corroles and the reference dye at the excitation wavelength) in EtOH : THF $(9: 1 \mathrm{v} / \mathrm{v})$ were placed in a $1 \mathrm{~cm}$ screw-cap quartz cuvette which was irradiated with the light of a xenon lamp using Fluorolog 3 spectrometer $\left(\lambda_{\max } 595 \mathrm{~nm}, 10 \mathrm{~nm}\right.$ slit, photon flux $\sim 175 \mu \mathrm{mol} \mathrm{s}^{-1} \mathrm{~m}^{-2}$ ). The solution was stirred during irradiation and the cuvette was shaken before acquisition of the absorption spectra. The curve was constructed as an average of 3 independent bleaching experiments. Quantum yields of singlet oxygen production $\Phi_{\Delta}$ were determined from the slope of the curve (absorbance at $358 \mathrm{~nm}$ vs. time) using methylene blue as a standard $\left(\Phi_{\Delta}\right.$ of 0.48 which is the average value from the data reported by Gross et al. ${ }^{54}$ and Usui et $a l^{55}{ }^{55}$.

\section{Results and discussion}

\section{Photophysical properties of $\mathrm{Os}^{\mathrm{VI}} \mathrm{N}$ corroles}

The ${ }{ }^{\mathrm{VI}} \mathrm{N}$ corroles studied (see structures depicted in Fig. 1) exhibit strong absorption in the blue and orange parts of the electromagnetic spectrum and room-temperature phosphorescence in the NIR region (Fig. 1 and Table 1). Observe that the spectra are slightly susceptible to substituent effects. Thus, both the $\mathrm{Q}$ band maxima and the emission maxima slightly shift bathochromically with increasing electron-donating character of

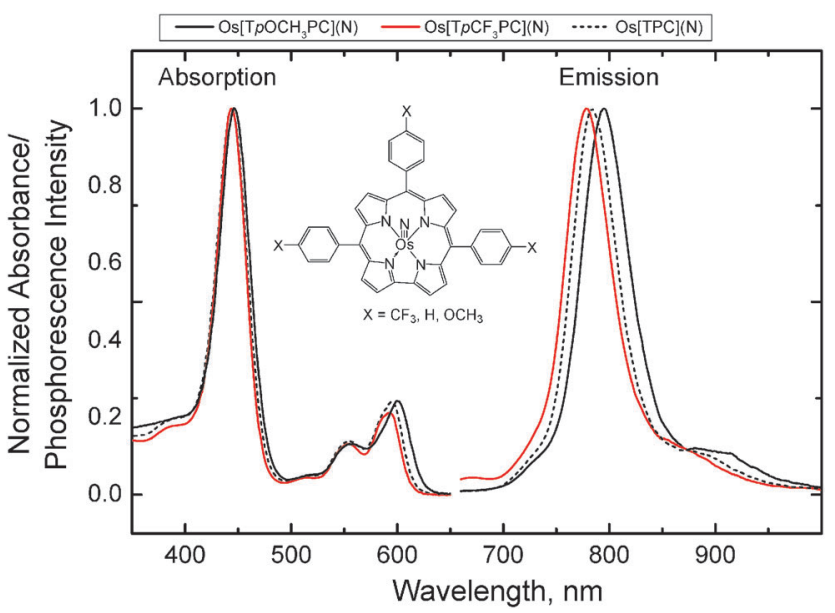

Fig. 1 Absorption and emission spectra of $\mathrm{Os}^{\mathrm{V} \mid} \mathrm{N}$ corroles in toluene $\left(25^{\circ} \mathrm{C}, \lambda_{\text {ex }} 595 \mathrm{~nm}\right)$. 
Table 1 Photophysical properties of $O s^{V /} \mathrm{N}$ corroles in anoxic toluene solutions

\begin{tabular}{|c|c|c|c|c|c|}
\hline Complex & $\begin{array}{l}\lambda_{\max (\mathrm{abs})} \\
\mathrm{nm}\end{array}$ & $\begin{array}{l}\varepsilon \times 10^{-4} \\
\mathrm{M}^{-1} \mathrm{~cm}^{-1}\end{array}$ & $\begin{array}{l}\lambda_{\max (\mathrm{em})} \\
\mathrm{nm}\end{array}$ & $\Phi, \%$ & $\begin{array}{l}\tau, 25{ }^{\circ} \mathrm{C}, \\
\mu \mathrm{s}\end{array}$ \\
\hline $\mathrm{Os}\left[\mathrm{T} p \mathrm{OCH}_{3} \mathrm{PC}\right](\mathrm{N})$ & $\begin{array}{l}447,558, \\
601\end{array}$ & $\begin{array}{l}8.31,1.18, \\
2.14\end{array}$ & 795 & 0.9 & 110 \\
\hline $\mathrm{Os}[\mathrm{TPC}](\mathrm{N})$ & $\begin{array}{l}444,555, \\
595\end{array}$ & $\begin{array}{l}9.32,1.28, \\
2.27\end{array}$ & 784 & 1.3 & 128 \\
\hline $\mathrm{Os}\left[\mathrm{T} p \mathrm{CF}_{3} \mathrm{PC}\right](\mathrm{N})$ & $\begin{array}{l}444,554, \\
593\end{array}$ & $\begin{array}{l}8.02,1.07, \\
1.73\end{array}$ & 779 & 1.3 & 150 \\
\hline
\end{tabular}

the para-substituent, i.e., $\mathrm{Os}\left[\mathrm{T} p \mathrm{OCH}_{3} \mathrm{PC}\right](\mathrm{N})>\mathrm{Os}[\mathrm{TPC}](\mathrm{N})>$ $\mathrm{Os}\left[\mathrm{T} p \mathrm{CF}_{3} \mathrm{PC}\right](\mathrm{N})$. Importantly for practical applications, the dyes can be excited with bright $590 \mathrm{~nm}$ and $605 \mathrm{~nm}$ LEDs.

The phosphorescence decay times for all the complexes are rather long $(>100 \mu \mathrm{s})$ and are intermediate between those of $\mathrm{Pt}(\mathrm{II})(\tau \sim 50-70 \mu \mathrm{s})$ and $\mathrm{Pd}(\mathrm{II})$ porphyrins $(\tau \sim 300-1000 \mu \mathrm{s})$. The shortest phosphorescence lifetime is exhibited by $\mathrm{Os}\left[\mathrm{T} p \mathrm{OCH}_{3} \mathrm{PC}\right](\mathrm{N})$ and the longest by $\mathrm{Os}\left[\mathrm{T} \mathrm{CF}_{3} \mathrm{PC}\right](\mathrm{N})$. This correlates well with the spectral properties of the dyes and the phosphorescence quantum yields. The quantum yields in solution are moderate, but nevertheless considerably higher than for the majority of phosphorescent iridium(III) corroles reported in the literature $\left(<0.01 \%,{ }^{43} 0.033-1.2 \%{ }^{44}\right)$.

The photostability of dyes, a key parameter for all applications, was investigated via irradiation of $1.4 \times 10^{-5} \mathrm{M}$ solutions of the complexes in air-saturated toluene with the light of a high power orange LED array (photon flux density $\left.10800 \mu \mathrm{mol} \mathrm{s}^{-1} \mathrm{~m}^{-2}\right)$ whose emission wavelength $\left(\lambda_{\max } 590 \mathrm{~nm}\right)$ almost perfectly matched the Q-bands of the dyes. No visible photodegradation was observed for $\mathrm{Os}\left[\mathrm{T} \mathrm{CF}_{3} \mathrm{PC}\right](\mathrm{N})$ (Fig. S1, ESI $\dagger$ ) and Os[TPC](N) after $30 \mathrm{~min}$ of continuous irradiation, indicating excellent photostability of these two dyes. $\mathrm{Os}\left[\mathrm{T} p \mathrm{OCH}_{3} \mathrm{PC}\right](\mathrm{N})$ appeared to be slightly less photostable and $\sim 1.1 \%$ dye degradation could be detected under the same conditions (Fig. S2, ESI $\dagger$ ), whereas after $6 \mathrm{~h}$ of irradiation bleaching of $\sim 4.9 \%$ of the dye was observed. The lower photostability of $\mathrm{Os}\left[\mathrm{T} p \mathrm{OCH}_{3} \mathrm{PC}\right](\mathrm{N})$ is presumably due to the electron-donating character of the methoxy groups in the paraposition of the meso-phenyl substituents, which may favour oxidation of the dye by singlet oxygen.

\section{Oxygen sensing properties of the $O \mathrm{Os}^{\mathrm{VI}} \mathrm{N}$ corroles}

The phosphorescence of the corroles is almost completely quenched by molecular oxygen in solutions of organic solvents, which makes them potentially suitable for application as oxygensensing materials. Accordingly, oxygen sensors were prepared by immobilizing the corroles into polystyrene ( $1 \mathrm{wt} \%$ of the indicator) along with $\mathrm{TiO}_{2}$ nanoparticles used as a light-scattering material to increase brightness. Although many other polymers could be used, polystyrene was chosen for its high chemical stability, good compatibility with the indicator dyes, and for simple comparisons with state-of-the-art materials. The resulting planar sensors exhibit adequate brightness under excitation with a $590 \mathrm{~nm}$ orange LED. The positions of the absorption bands are not affected by immobilization and the phosphorescence spectra are also very similar to those obtained in the toluene solution (Fig. S3, ESI $\dagger$ and Table 2). The phosphorescent decay times are slightly higher in polystyrene relative to the solutions (Tables 1 and 2), reflecting less efficient radiationless deactivation in a rigid matrix. The $\Phi$ values are approximately $1 \%$ and are comparable to the values obtained in solution.

Fig. 2 shows a representative calibration plot obtained with phase fluorometry. Whereas the Stern-Volmer plots for fluorescence intensity are almost linear (correlation coefficient $r^{2}$ 0.998), the decay time plots deviate significantly from linearity. Such behaviour is in fact typical for oxygen sensors and very few matrices exhibit near-linear decay time plots. The nonlinear plots can be described with an equation derived from a so-called "two-site model" that assumes localization of the dye in two different environments: ${ }^{56}$

$$
\frac{I}{I_{0}}=\frac{\tau}{\tau_{0}}=\frac{f}{1+K_{\mathrm{SV}}^{1}\left[\mathrm{O}_{2}\right]}+\frac{1-f}{1+K_{\mathrm{SV}}^{2}\left[\mathrm{O}_{2}\right]},
$$

where $f$ is the fraction of the total emission for the first microenvironment, and $K_{\mathrm{SV}}^{1}$ and $K_{\mathrm{SV}}^{2}$ are the Stern-Volmer constants for each component. $K_{\mathrm{SV}}^{2}=K_{\mathrm{SV}}^{1} \times m$.

Although the two-site model is physically meaningful only for the luminescence intensity, the decay time plots can also be almost perfectly fit with the above equation $\left(r^{2}\right.$ 0.9999). The Stern-Volmer constants obtained from the fit are summarized in Table 2. Evidently, the sensors are promising for oxygen sensing from hypoxia to air saturation. Consistent with differences in luminescence decay times, the sensitivity is the highest for $\mathrm{Os}\left[\mathrm{T} p \mathrm{CF}_{3} \mathrm{PC}\right](\mathrm{N})$ and the lowest for $\mathrm{Os}\left[\mathrm{T} p \mathrm{OCH}_{3} \mathrm{PC}\right](\mathrm{N})$-based sensors. The sensitivity of the sensor can thus be tailored to a specific application simply by varying the nature of the complex used. Obviously, much more substantial modulation of the sensitivity should be possible by substitution of polystyrene with a polymer with higher/lower oxygen permeability. Table 2 also shows that the bimolecular quenching constant $k_{\mathrm{q}}=K_{\mathrm{SV}} / \tau_{0}$ is very similar for all the complexes examined.

Fig. 2 evinces temperature cross-talk of the oxygen sensor, a well-known phenomenon that originates from two main factors:

Table 2 Photophysical and sensing properties of the oxygen sensors based on $\mathrm{Os}^{\mathrm{V} / \mathrm{N}}$ corroles

\begin{tabular}{|c|c|c|c|c|c|c|c|c|}
\hline Complex & $\begin{array}{l}\lambda_{\max (\mathrm{abs})}, \\
\mathrm{nm}\end{array}$ & $\begin{array}{l}\lambda_{\max (\mathrm{em})}, \\
\mathrm{nm}\end{array}$ & $\Phi,{ }^{a} \%$ & $\begin{array}{l}\tau_{0} \text { at } 25{ }^{\circ} \mathrm{C}, \\
\mu \mathrm{S}\end{array}$ & $\begin{array}{l}K_{\mathrm{SV}}^{1} \text { at } 25{ }^{\circ} \mathrm{C} \\
\mathrm{kPa}^{-1 b}\end{array}$ & $\begin{array}{l}K_{\mathrm{SV}} \text { at } 25^{\circ} \mathrm{C}, \\
\mathrm{kPa}^{-1 c}\end{array}$ & $\begin{array}{l}k_{\mathrm{q}} \text { at } 25^{\circ} \mathrm{C}, \\
\mathrm{Pa}^{-1} \mathrm{~cm}^{-1 c}\end{array}$ & $\begin{array}{l}\mathrm{d} \tau_{0} / \mathrm{d} T \text { at } 25{ }^{\circ} \mathrm{C}, \\
\% \mathrm{~K}^{-1}\end{array}$ \\
\hline $\mathrm{Os}\left[\mathrm{T} p \mathrm{OCH}_{3} \mathrm{PC}\right](\mathrm{N})$ & $447,557,601$ & 787 & 0.72 & 136 & 0.91 & 0.40 & 2.9 & -0.203 \\
\hline $\mathrm{Os}\left[\mathrm{T} p \mathrm{CF}_{3} \mathrm{PC}\right](\mathrm{N})$ & $444,553,593$ & 771 & 0.95 & 183 & 1.38 & 0.56 & 3.0 & -0.136 \\
\hline
\end{tabular}

${ }^{a}$ Anoxic conditions. ${ }^{b}$ Decay time Stern-Volmer plots; fit parameters: $m=0.08 ; f=0.68$ for all optodes. ${ }^{c}$ Intensity Stern-Volmer plots. 

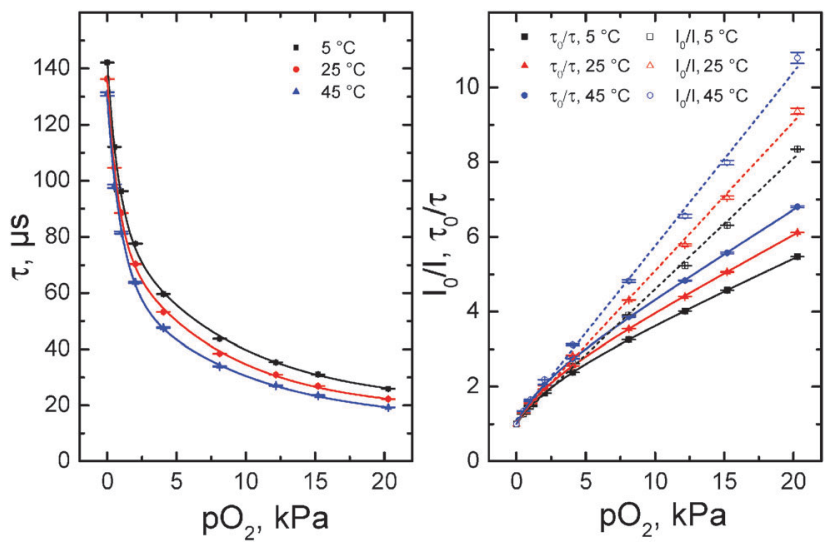

Fig. 2 Decay time (left) and Stern-Volmer plots (right) for the oxygen sensor based on $\mathrm{Os}\left[\mathrm{TpOCH} \mathrm{CHC}_{3} \mathrm{PC}\right.$ ) in polystyrene. Eqn (1) was used to fit the decay time Stern-Volmer plots, whereas a linear fit was used in case of the intensity plots.

(i) thermal quenching of phosphorescence, which is the main error source at low $p \mathrm{O}_{2}$ close to the limit of detection, and (ii) temperature-dependent diffusion and solubility of oxygen in the matrix polymer. Thermal quenching of the $\mathrm{Os}^{\mathrm{VI}} \mathrm{N}$ complexes is relatively small as indicated by the temperature coefficients of $\tau_{0}$ in the range from 0.13 to $0.20 \% \mathrm{~K}^{-1}$ (Table 2). Notably, popular oxygen indicators such as $\mathrm{Pd}(\mathrm{II})$ porphyrins and particularly $\mathrm{Ru}(\mathrm{II})$ polypyridyl complexes show significantly higher temperature sensitivity of $\tau_{0}\left(\mathrm{~d} \tau_{0} / \mathrm{d} T \sim 0.33 \% \mathrm{~K}^{-1}\right.$ (ref. 57 ) and $\sim 0.5 \% \mathrm{~K}^{-1},{ }^{58}$ respectively). Interestingly, thermal quenching is less efficient in case of $\mathrm{Os}\left[\mathrm{T} \mathrm{CF}_{3} \mathrm{PC}\right](\mathrm{N})$ and is the highest for $\mathrm{Os}\left[\mathrm{T} p \mathrm{OCH}_{3} \mathrm{PC}\right](\mathrm{N})$. This correlates well with the phosphorescence quantum yields obtained at room temperature. As with other oxygen indicators in polystyrene, quenching becomes more efficient at higher temperatures (Fig. 2 and Table S1, ESI $\dagger$ ). Despite that the Stern-Volmer constants $K_{\mathrm{SV}}$ are different for the three corroles, the bimolecular quenching constants $k_{\mathrm{q}}$ are very similar (Table S1, ESI $\dagger$ ).

The stability and reversibility of the sensors was investigated by continuous irradiation with a $455 \mathrm{~nm}$ LED (Fig. 3), which also reflects their photostability. Since the photostability of the dyes may vary significantly for anoxic conditions and air saturation (due to generation of highly reactive singlet oxygen), we tested it under both conditions. Fig. 3 shows that stability of the optode based on the $\mathrm{Os}\left[\mathrm{T} p \mathrm{OCH}_{3} \mathrm{PC}\right](\mathrm{N})$ complex is excellent. In fact, the intensity decreases by only $4 \%$ after the first $2.5 \mathrm{~h}$ of irradiation, and by only $5 \%$ after $6.5 \mathrm{~h}$, indicating that bleaching is even slower after initial period. Also, no changes in the luminescence decay time were observed during the duration of the experiment. It may be noted that $1 \mathrm{~h}$ of continuous irradiation corresponds to about 200000 measurement points under standard conditions (integration time $20 \mathrm{~ms}$ ), emphasizing the suitability of the materials for prolonged measurements as well as for measurements at high light intensity (e.g., in microscopy). Analogously to the optode based on $\mathrm{Os}\left[\mathrm{T} p \mathrm{OCH}_{3} \mathrm{PC}\right](\mathrm{N})$, the sensors based on the other $\mathrm{Os}^{\mathrm{VI}} \mathrm{N}$ corroles also showed excellent stability.
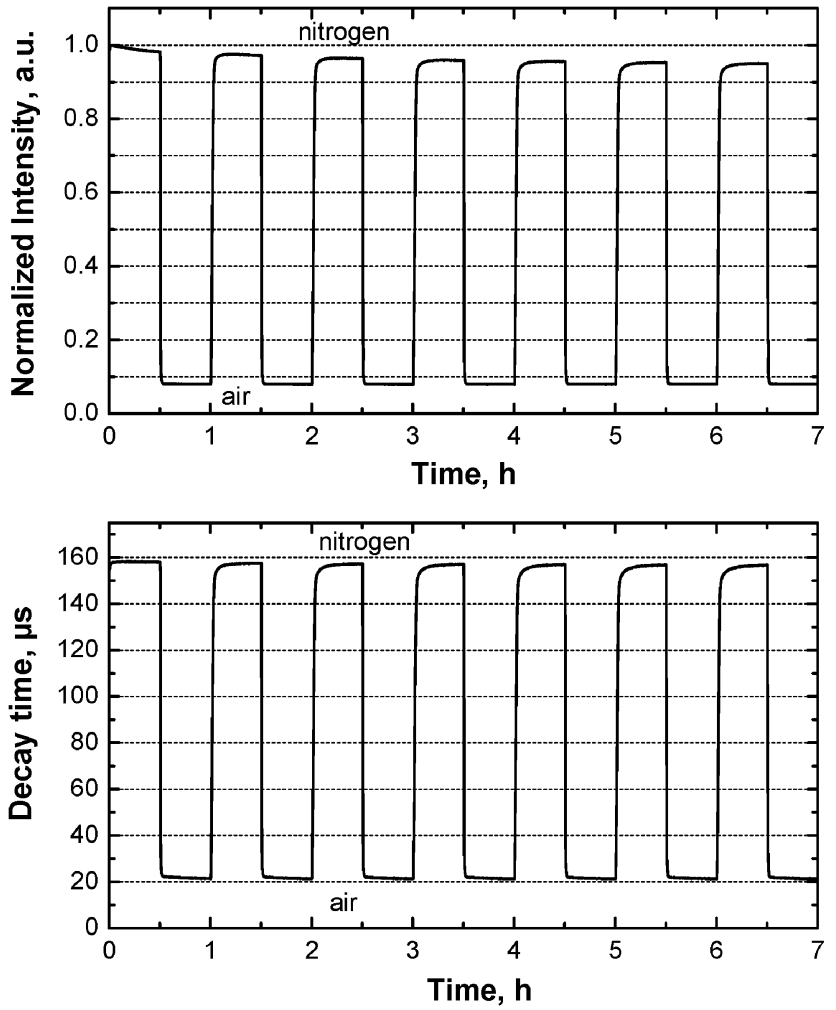

Fig. 3 Intensity (above) and decay time (below) profiles for the oxygen sensor based on $\mathrm{Os}\left[\mathrm{TpOCH}{ }_{3} \mathrm{PC}\right](\mathrm{N})$ in polystyrene upon continuous excitation with a $455 \mathrm{~nm} \operatorname{LED}\left(25^{\circ} \mathrm{C}\right)$.

\section{${ }^{\mathrm{Os}}{ }^{\mathrm{VI}} \mathrm{N}$ corroles as sensitizers in triplet-triplet annihilation- based upconversion}

The room-temperature phosphorescence of the ${ }^{\mathrm{V}}{ }^{\mathrm{VI}} \mathrm{N}$ corroles and the relatively long phosphorescence decay times suggested that these dyes are potentially suitable as sensitizers in triplettriplet-annihilation-based upconversion systems. Their absorption in the orange part of the spectrum is particularly attractive, since the number of sensitizers available for this part of the spectrum is still limited. Anoxic toluene solutions containing $1 \times 10^{-4} \mathrm{M}$ of an $\mathrm{Os}^{\mathrm{VI}} \mathrm{N}$ corrole as a sensitizer (S) and $2.5 \times 10^{-4} \mathrm{M}$ of an annihilator (A, perylene or SG 5) indeed exhibit intense upconverted emission from the annihilator, which is clearly visible even under excitation with a $590 \mathrm{~nm}$ LED (Fig. 4). Under excitation with orange light $\left(\lambda_{\text {ex }} 595 \mathrm{~nm}\right)$, the following processes occur:

$$
\begin{gathered}
\mathrm{S}\left(\mathrm{S}_{0}\right)+h \nu \rightarrow \mathrm{S}^{*}\left(\mathrm{~T}_{1}\right) \\
\mathrm{S}^{*}\left(\mathrm{~T}_{1}\right)+\mathrm{A}\left(\mathrm{S}_{0}\right) \rightarrow \mathrm{S}\left(\mathrm{S}_{0}\right)+\mathrm{A}^{*}\left(\mathrm{~T}_{1}\right) \\
\mathrm{A}^{*}\left(\mathrm{~T}_{1}\right)+\mathrm{A}^{*}\left(\mathrm{~T}_{1}\right) \rightarrow \mathrm{A}^{*}\left(\mathrm{~S}_{1}\right)+\mathrm{A}\left(\mathrm{S}_{0}\right) \\
\mathrm{A}^{*}\left(\mathrm{~S}_{1}\right) \rightarrow \mathrm{A}\left(\mathrm{S}_{0}\right)+h \nu^{\prime}
\end{gathered}
$$

Among the three corroles investigated, Os[TPC](N) exhibits the brightest upconverted emission (Fig. 5A). The quantum yields for the upconverted fluorescence were estimated to be 

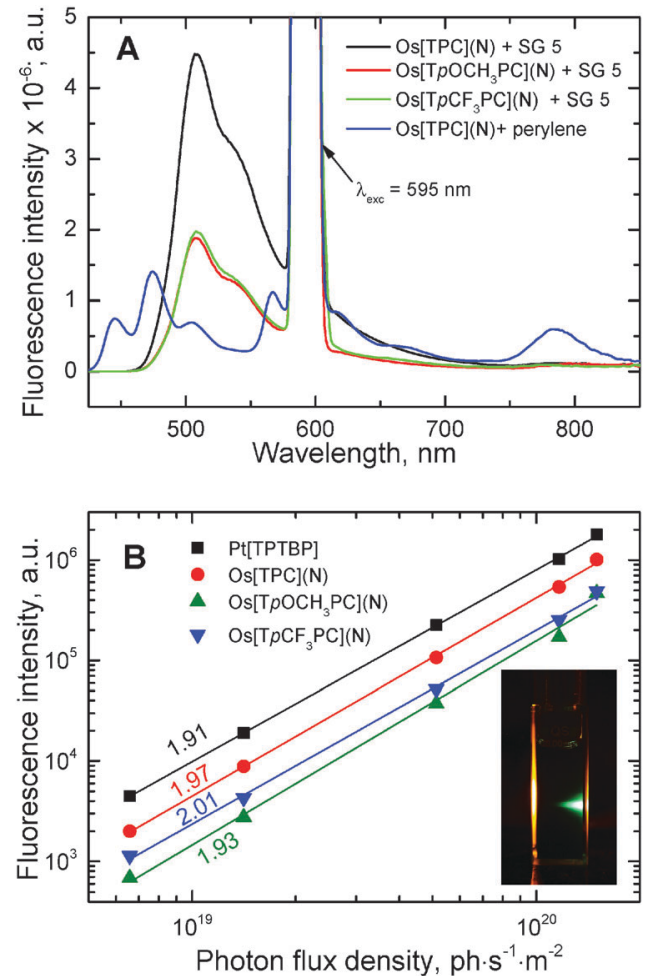

Fig. 4 Panel A: Emission spectra of anoxic toluene solutions containing $1 \times 10^{-4} \mathrm{M}$ of an Os ${ }^{\mathrm{V} / \mathrm{N}}$ corrole and $2.5 \times 10^{-4} \mathrm{M}$ of annihilator ( $\lambda_{\text {exc }} 595 \mathrm{~nm}$ ). Panel B: Dependence of the intensity of upconverted fluorescence $(\lambda=505 \mathrm{~nm})$ on the power density of the excitation light with slopes of the curve indicated. The inset shows a photographic image of anoxic toluene solution containing $1 \times 10^{-4} \mathrm{M}$ of $\mathrm{Os}^{\mathrm{VI}}[\mathrm{TPC}](\mathrm{N})$ and $2.5 \times 10^{-4} \mathrm{M}$ of annihilator SG 5 under excitation with a 590 nm LED.

$2.0, \quad 0.9$, and $0.8 \%$ for $\operatorname{Os}[\mathrm{TPC}](\mathrm{N}), \operatorname{Os}\left[\mathrm{T} p \mathrm{CF}_{3} \mathrm{PC}\right](\mathrm{N})$ and $\mathrm{Os}\left[\mathrm{T} p \mathrm{OCH}_{3} \mathrm{PC}\right](\mathrm{N})$, respectively, when using SG 5 as the annihilator, and $0.51,0.11$ and $0.15 \%$, with perylene as annihilator. The significantly lower upconversion quantum yields for perylene relative to SG 5 may be attributed to less efficient triplettriplet energy transfer from the sensitizer to the annihilator as a result of the relatively high energy of the triplet state of perylene. Indeed, residual phosphorescence from the sensitizer is visible when perylene is used as annihilator whereas it vanishes completely in case of SG 5 (Fig. 4A).

For comparison, the upconverted fluorescence quantum yield for the commonly used sensitizer Pt[TPTBP] were estimated to be 3.6 and $1.8 \%$, when using SG 5 and perylene as annihilators, respectively. It should be noted that all the quantum yields are expected to be significantly higher at higher intensities of the excitation light, which were unfortunately not attainable with our experimental set-up. In fact, all the experimental points exhibit a quadratic dependency of the emission intensity on the intensity of the excitation light well below the saturation limit as indicated by the slope of the double logarithmic plots ${ }^{59}$ close to 2.0 (Fig. 4B).

\section{$\mathrm{Os}^{\mathrm{VI}} \mathrm{N}$ corroles as singlet oxygen sensitizers}

Singlet oxygen sensitizers are of high interest mostly due to their application in photodynamic therapy of cancer ${ }^{60}$ but also

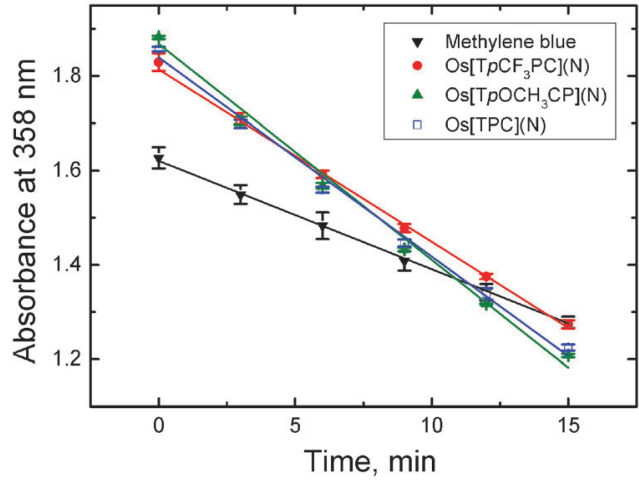

Fig. 5 Degradation profiles of 9,10-dimethylanthracene $(0.28 \mathrm{mM})$ in an airsaturated solution (9:1 EtOH/THF) in presence of a sensitizer ( $15 \mu \mathrm{M})$ upon excitation with orange light ( $595 \pm 5 \mathrm{~nm}$; photon flux $\sim 175 \mu \mathrm{mol} \mathrm{s}{ }^{-1} \mathrm{~m}^{-2}$ ). Absorption spectra for all the systems are provided in ESI $\dagger$ (Fig. S4-S7).

as singlet oxygen generators for photocatalytic applications ${ }^{61,62}$ and for disinfection purposes. ${ }^{63} \mathrm{Os}^{\mathrm{VI}} \mathrm{N}$ corroles might be attractive for these applications due to long-wavelength absorption and high stability. Fig. 5 illustrates the determination of singlet oxygen quantum yields $\Phi_{\Delta}$ with a chemical method using 9,10-dimethylanthracene as a singlet oxygen acceptor. ${ }^{54}$ Methylene blue $\left(\Phi_{\Delta}=0.48\right.$, an average value from the data reported by Gross et al. ${ }^{54}$ and Usui et $a .^{55}$ ) was used as the reference dye. All three complexes were found to be efficient generators of singlet oxygen, with $\Phi_{\Delta}$ 's of $0.95,0.88$ and 0.76 for $\mathrm{Os}\left[\mathrm{T} p \mathrm{OCH}_{3} \mathrm{PC}\right](\mathrm{N}), \mathrm{Os}[\mathrm{TPC}](\mathrm{N})$ and $\mathrm{Os}\left[\mathrm{T} \mathrm{CF}_{3} \mathrm{PC}\right](\mathrm{N})$, respectively. Interestingly, this trend is opposite to that observed for the phosphorescence quantum yields and decay times (Table 1). We may conclude that osmium-nitrido corroles show comparable or higher efficiency of ${ }^{1} \mathrm{O}_{2}$ sensitization than the metal-free corroles and the respective $\mathrm{Ga}(\mathrm{III})$ complexes $\left(\Phi_{\Delta} 0.34-0.86 ;^{64}\right.$ $\left.0.51-0.77^{65}\right)$ and are much more powerful ${ }^{1} \mathrm{O}_{2}$ generators than $\operatorname{Ir}(\mathrm{III})$ corroles $\left(\Phi_{\Delta} 0.09-0.15\right){ }^{43}$

\section{Conclusions}

Osmium(vI)-nitrido corroles represent a new class of NIR phosphorescent materials with relatively long decay times and high photostability. Although the luminescence quantum yields are moderate, they are significantly higher than those of the majority of phosphorescent corroles reported up to date. Furthermore, we have shown that ${ }^{\mathrm{V}}{ }^{\mathrm{VI}} \mathrm{N}$ corroles can be used as indicators for optical oxygen sensors, as highly efficient singlet oxygen sensitizers, and as triplet sensitizers in organic upconversion systems, where high photostability of the dyes is of primary importance.

\section{Acknowledgements}

This project was partly supported by a FRINATEK project no. 231086 of the Research Council of Norway (AG). The authors thank Matthias Schwar (Graz University of Technology) for technical support. 


\section{References}

1 R. C. Evans, P. Douglas and C. J. Winscom, Coord. Chem. Rev., 2006, 250, 2093-2126.

2 J. Kalinowski, V. J. Kalinowski, V. Fattori, M. Cocchi and J. A. G. Williams, Coord. Chem. Rev., 2011, 255, 2401-2425.

3 Q. Zhao, F. Li and C. Huang, Chem. Soc. Rev., 2010, 39, 3007-3030.

4 M. Schäferling, Angew. Chem., Int. Ed., 2012, 51, 3532-3554.

5 Q. Zhao, C. Huang and F. Li, Chem. Soc. Rev., 2011, 40, 2508-2524.

6 D. B. Papkovsky and T. C. O’Riordan, J. Fluoresc., 2005, 15, 569-584.

7 T. N. Singh-Rachford and F. N. Castellano, Coord. Chem. Rev., 2010, 254, 2560-2573.

8 J. Zhao, S. Ji and H. Guo, RSC Adv., 2011, 1, 937-950.

9 J. Zhou, Q. Liu, W. Feng, Y. Sun and F. Li, Chem. Rev., 2015, 115, 395-465.

10 J. Zhao, W. Wu, J. Sun and S. Guo, Chem. Soc. Rev., 2013, 42, 5323-5351.

11 H. Xiang, J. Cheng, X. Ma, X. Zhou and J. J. Chruma, Chem. Soc. Rev., 2013, 42, 6128-6185.

12 C. Borek, K. Hanson, P. I. Djurovich, M. E. Thompson, K. Aznavour, R. Bau, Y. Sun, S. R. Forrest, J. Brooks, L. Michalski and J. Brown, Angew. Chem., Int. Ed., 2007, 46, 1109-1112.

13 J. R. Sommer, R. T. Farley, K. R. Graham, Y. Yang, J. R. Reynolds, J. Xue and K. S. Schanze, ACS Appl. Mater. Interfaces, 2009, 1, 274-278.

14 K. R. Graham, Y. Yang, J. R. Sommer, A. H. Shelton, K. S. Schanze, J. Xue and J. R. Reynolds, Chem. Mater., 2011, 23, 5305-5312.

15 M. J. Currie, J. K. Mapel, T. D. Heidel, S. Goffri and M. A. Baldo, Science, 2008, 321, 226-228.

16 E. Roussakis, Z. Li, A. J. Nichols and C. L. Evans, Angew. Chem., Int. Ed., 2015, 54, 8340-8362.

17 R. I. Dmitriev and D. B. Papkovsky, Cell. Mol. Life Sci., 2012, 69, 2025-2039.

18 C. Staudinger and S. M. Borisov, Methods Appl. Fluoresc., 2015, 3, 042005.

19 A. Y. Lebedev, A. V. Cheprakov, S. Sakadžić, D. A. Boas, D. F. Wilson and S. A. Vinogradov, ACS Appl. Mater. Interfaces, 2009, 1, 1292-1304.

20 B. Nacht, C. Larndorfer, S. Sax, S. M. Borisov, M. Hajnsek, F. Sinner, E. J. W. List-Kratochvil and I. Klimant, Biosens. Bioelectron., 2015, 64, 102-110.

21 S. A. Vinogradov and D. F. Wilson, J. Chem. Soc., Perkin Trans. 2, 1995, 103-111.

22 O. S. Finikova, A. V. Cheprakov, I. P. Beletskaya, P. J. Carroll and S. A. Vinogradov, J. Org. Chem., 2004, 69, 522-535.

23 V. V. Rozhkov, M. Khajehpour and S. A. Vinogradov, Inorg. Chem., 2003, 42, 4253-4255.

24 O. S. Finikova, A. V. Cheprakov, P. J. Carroll and S. A. Vinogradov, J. Org. Chem., 2003, 68, 7517-7520.

25 S. M. Borisov, R. Saf, R. Fischer and I. Klimant, Inorg. Chem., 2013, 52, 1206-1216.
26 W. Wu, J. Zhao, H. Guo, J. Sun, S. Ji and Z. Wang, Chem. Eur. J., 2012, 18, 1961-1968.

27 W. Wu, L. Liu, X. Cui, C. Zhang and J. Zhao, Dalton Trans., 2013, 42, 14374-14379.

28 F. Zhong, A. Karatay, L. Zhao, J. Zhao, C. He, C. Zhang, H. G. Yaglioglu, A. Elmali, B. Küçüköz and M. Hayvali, Inorg. Chem., 2015, 54, 7803-7817.

29 Y. Liu, W. Wu, J. Zhao, X. Zhang and H. Guo, Dalton Trans., 2011, 40, 9085-9089.

30 L. Liu, S. Guo, J. Ma, K. Xu, J. Zhao and T. Zhang, Chem. - Eur. J., 2014, 20, 14282-14295.

31 A. Kamkaew, S. H. Lim, H. B. Lee, L. V. Kiew, L. Y. Chung and K. Burgess, Chem. Soc. Rev., 2013, 42, 77-88.

32 J. Zhao, K. Xu, W. Yang, Z. Wang and F. Zhong, Chem. Soc. Rev., 2015, 44, 8904-8939.

33 I. Aviv and Z. Gross, Chem. Commun., 2007, 1987-1999.

34 K. E. Thomas, A. B. Alemayehu, J. Conradie, C. M. Beavers and A. Ghosh, Acc. Chem. Res., 2012, 45, 1203-1214.

35 H. L. Buckley and J. Arnold, Dalton Trans., 2015, 44, 30-36. 36 J. H. Palmer, in Molecular Electronic Structures of Transition Metal Complexes I, ed. D. M. P. Mingos, P. Day and J. P. Dahl, Springer, Berlin Heidelberg, 2011, pp. 49-89.

37 L. Simkhovich and Z. Gross, Tetrahedron Lett., 2001, 42, 8089-8092.

38 I. Aviv-Harel and Z. Gross, Chem. - Eur. J., 2009, 15, 8382-8394. 39 L. Tortora, G. Pomarico, S. Nardis, E. Martinelli, A. Catini, A. D'Amico, C. Di Natale and R. Paolesse, Sens. Actuators, B, 2013, 187, 72-77.

40 I. Aviv-Harel and Z. Gross, Coord. Chem. Rev., 2011, 255, 717-736.

41 A. Ghosh and M. Ravikanth, Chem. - Eur. J., 2012, 18, 6386-6396.

42 J. J. Weaver, K. Sorasaenee, M. Sheikh, R. Goldschmidt, E. Tkachenko, Z. Gross and H. B. Gray, J. Porphyrins Phthalocyanines, 2004, 08, 76-81.

43 W. Sinha, L. Ravotto, P. Ceroni and S. Kar, Dalton Trans., 2015, 44, 17767-17773.

44 J. H. Palmer, A. C. Durrell, Z. Gross, J. R. Winkler and H. B. Gray, J. Am. Chem. Soc., 2010, 132, 9230-9231.

45 E. Rabinovich, I. Goldberg and Z. Gross, Chem. - Eur. J., 2011, 17, 12294-12301.

46 J. Vestfrid, I. Goldberg and Z. Gross, Inorg. Chem., 2014, 53, 10536-10542.

47 R. F. Einrem, K. J. Gagnon, A. B. Alemayehu and A. Ghosh, Chem. - Eur. J., 2016, 22, 517-520.

48 A. B. Alemayehu, K. J. Gagnon, J. Terner and A. Ghosh, Angew. Chem., Int. Ed., 2014, 53, 14411-14414.

49 A. B. Alemayehu and A. Ghosh, J. Porphyrins Phthalocyanines, 2011, 15, 106-110.

50 K. E. Thomas, A. B. Alemayehu, J. Conradie, C. Beavers and A. Ghosh, Inorg. Chem., 2011, 50, 12844-12851.

51 K. E. Thomas, C. M. Beavers and A. Ghosh, Mol. Phys., 2012, 110, 2439-2444.

52 A. B. Alemayehu, H. Vazquez-Lima, C. M. Beavers, K. J. Gagnon, J. Bendix and A. Ghosh, Chem. Commun., 2014, 50, 11093-11096.

53 S. M. Borisov, G. Nuss, W. Haas, R. Saf, M. Schmuck and I. Klimant, J. Photochem. Photobiol., A, 2009, 201, 128-135. 
54 E. Gross, B. Ehrenberg and F. M. Johnson, Photochem. Photobiol., 1993, 57, 808-813.

55 Y. Usui, H. Koike and Y. Kurimura, Bull. Chem. Soc. Jpn., 1987, 60, 3373-3378.

56 E. R. Carraway, J. N. Demas, B. A. DeGraff and J. R. Bacon, Anal. Chem., 1991, 63, 337-342.

57 S. M. Borisov, G. Nuss and I. Klimant, Anal. Chem., 2008, 80, 9435-9442.

58 S. M. Borisov and I. Klimant, Anal. Chem., 2007, 79, 7501-7509.

59 A. Monguzzi, J. Mezyk, F. Scotognella, R. Tubino and F. Meinardi, Phys. Rev. B: Condens. Matter Mater. Phys., 2008, 78, 195112.
60 D. E. J. G. J. Dolmans, D. Fukumura and R. K. Jain, Nat. Rev. Cancer, 2003, 3, 380-387.

61 S. Hecht and J. M. J. Fréchet, J. Am. Chem. Soc., 2001, 123, 6959-6960.

62 J. Sun, J. Zhao, H. Guo and W. Wu, Chem. Commun., 2012, 48, 4169-4171.

63 L. Villén, F. Manjón, D. García-Fresnadillo and G. Orellana, Appl. Catal., B, 2006, 69, 1-9.

64 W. Shao, H. Wang, S. He, L. Shi, K. Peng, Y. Lin, L. Zhang, L. Ji and H. Liu, J. Phys. Chem. B, 2012, 116, 14228-14234.

65 B. Ventura, A. Degli Esposti, B. Koszarna, D. T. Gryko and L. Flamigni, New J. Chem., 2005, 29, 1559-1566. 